\title{
E-referrals to ENT: how have these changed our practice and how can we be more NICE?
}

\author{
Dr Grant S. Nolan, Benfield Park Medical Group, Newcastle-upon-Tyne, United Kingdom
}

Key Points

\begin{abstract}
- E-referrals to ENT have dramatically improved the quality of referrals compared to historic Irish data. - Standardised referrals still provide superior information compared with unstructured referrals.

- Referrals in-line with UK guidelines were more likely to undergo an ENT procedure. They may be more likely to require an operation.

- Some patients without NICE referral criteria do require procedures $\&$ operations from ENT, and GPs must continue to be allowed the flexibility to refer these patients if they see fit.
\end{abstract}

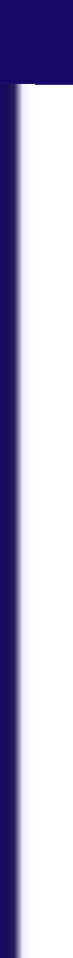

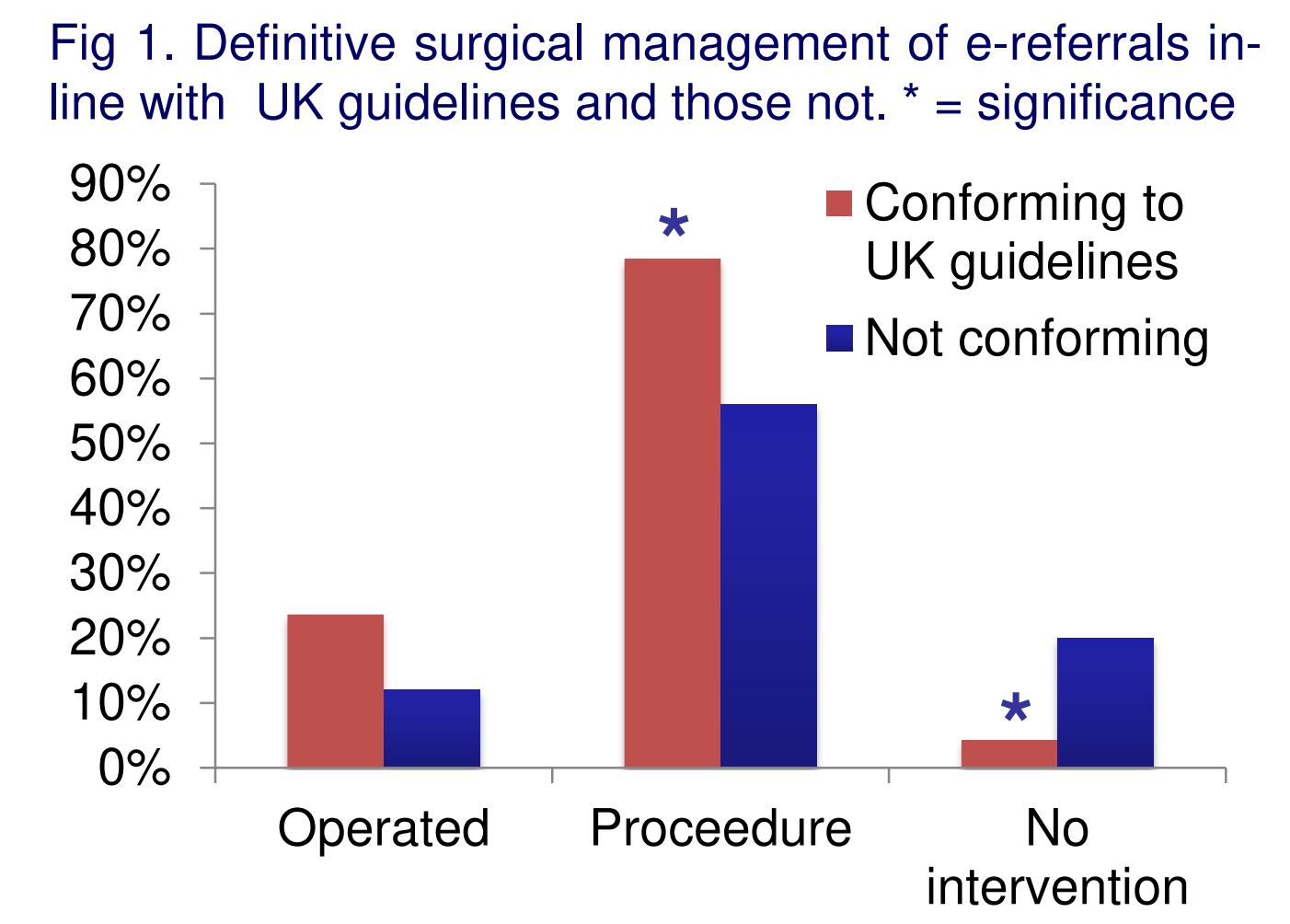

Fig 1. Definitive surgical management of e-referrals in-

\section{Background}

In 2014, Oosthuizen audited ENT referrals to a Dublin hospital against the Irish College of General Practitioners (ICGP) referral template and found that they only included on average 16/37 recommended details ${ }^{1}$. They suggested that standardised referral forms may provide superior information.

Aims

- To determine if e-referrals have improved the quality of referrals to ENT in a typical GP surgery in the United Kingdom.

- To determine if referrals are in-line with national UK guidelines and how this affects their definitive surgical management from ENT.

\section{Methods}

183 referrals between 05/04/2017 and 28/02/2018 from Benfield Park Medical Group were identified. Referrals to audiology and from other sources were excluded.

Referral quality was audited using Oosthuizen's methodology and the same ICGP template. Referrals were scored out of a maximum of 37 points by awarding 1 point per detail. These were grouped into referral details ( 6 points), patient details (12 points), referrer details (7 points), patient's usual GP (2 points) and clinical information (10 points).

The National Institute for Health and Care Excellence (NICE) referral criteria were determined using their online publications (current or in-progress) and Clinical Knowledge Summaries. Statistical analysis was undertaken using Chi-squared with significance of $p=$ 0.05 .

\section{Results}

118 referrals (92 written, 26 telephone and 2 telephone \& written) were included. 65 were excluded (40 to audiology and 25 from other sources.)

Were e-referrals in-line with UK guidelines and how did this affect management?

Of the 118 referrals, $93(79 \%)$ had a defined NICE or SIGN indication and 25 did not.

Patients with a NICE/SIGN referral criterion were more likely to have a procedure $(p=0.03)$ and less likely to have no intervention $(p<$ 0.01 ). There was a trend towards patients with a NICE/SIGN referral criterion being more likely to undergo an operation. (Not significant, $p=0.20$ ). See figure 1 .
What was the quality of the e-referrals?

Written e-referrals contained a median of 26/37 details (range 21 to 33). Urgent referrals were generally superior in terms of patient and referrer details with 'first language', 'interpreter required' and 'wheelchair assistance' being most commonly omitted.

Examinations findings were included more frequently in routine referrals but allergies and social history were more commonly found in urgent referrals. See table 1.

Table 1. Percentage compliance within each e-referral section in urgent and routine e-referrals, and compared to historic Irish data

\begin{tabular}{|l|c|c|c|c|}
\hline $\begin{array}{c}\text { Referral } \\
\text { section }\end{array}$ & $\begin{array}{c}\text { Urgent e- } \\
\text { referrals } \\
(\%)\end{array}$ & $\begin{array}{c}\text { Routine e- } \\
\text { referrals } \\
(\%)\end{array}$ & $\begin{array}{c}\text { Overall } \\
\text { compliance } \\
(\%)\end{array}$ & $\begin{array}{c}\text { Oosthuizen's } \\
\text { data from } \\
2014(\%)\end{array}$ \\
\hline $\begin{array}{l}\text { Referral } \\
\text { details }\end{array}$ & 70 & 70 & 70 & 42 \\
\hline $\begin{array}{l}\text { Patient } \\
\text { details }\end{array}$ & 87 & 52 & 64 & 41 \\
\hline $\begin{array}{l}\text { Referrer } \\
\text { details }\end{array}$ & 76 & 60 & 67 & 74 \\
\hline $\begin{array}{l}\text { Patient's } \\
\text { usual GP }\end{array}$ & 95 & 61 & 77 & 0 \\
\hline $\begin{array}{l}\text { Clinical } \\
\text { information }\end{array}$ & 82 & 75 & 78 & 35 \\
\hline Total & 80 & 64 & 71 & 44 \\
\hline
\end{tabular}

\section{Discussion}

Here we present data that e-referrals have drastically improved the quality of referrals (from an average of $16 / 37$ to 26/37 details).

Standardised forms which automatically pre-populate the ereferrals with details are likely responsible for this dramatic increase, suggested by the high level of compliance in urgent referrals where $83 \%$ were on a standardised form. It may be that GPs can be encouraged to provide clinical details that are often omitted by an effective IT system prompting them.

Of all the surgical specialities, ENT operate on the lowest proportion of their patients at only $15 \%^{2}$. Our data is similar, with $21 \%$ requiring an operation. Our data shows referral in-line with UK guidelines increase the chance of a patient requiring a specialist procedure from ENT, however interestingly there are still patients being operated on who do not fit into a NICE criterion. This data set adds weight to the notion that GPs are experts in their field, and specialists must continue to trust GPs clinical judgement, even if they deviate from guidelines.

References

1. Oosthuizen J, McShane D, Kinsella J, Conlon B. General practitioner ENT referral audit. Irish Journal of Medical Science (1971 -). 2014;184(1):143-146.

2. Ear, Nose \& Throat (ENT) - Royal College of Surgeons [Internet]. Royal College of Surgeons. 2018 [cited 26 June 2018]. Available from: https://www.rcseng.ac.uk/news-and-events/media-centre/media-background-briefings-and-statistics/ear-nose-and-throat 